\title{
Interdisciplinaridade no Ensino Médio Politécnico: O que pensam os professores?
}

Bedin, Everton'; Del Pino, José Claudio²

Categoria 2. Trabalhos de investigação.

\section{Resumo}

Este ensaio traz à discussão resultados de uma investigação crítico-reflexivo, realizada com um grupo de professores de uma escola público do norte do estado gaúcho, tendo por objetivo entender e refletir, por meio das concepções e percepções docentes à luz da interdisciplinaridade, as prioridades que compõem a aplicabilidade das atividades docentes no Ensino Médio Politécnico. Para a pesquisa de forma qualitativa, fez-se uso de questionário estruturado, onde se verificou que os professores incumbem à Políticas Públicas e Currículo Flexibilizado como as principais categorias para a emersão da interdisciplinaridade no trabalho docente à luz das atividades no Ensino Médio Politécnico. Não obstante, os mesmos asseguram que um trabalho pautado na interdisciplinaridade poderá contemplar o crescimento pessoal, intelectual e sócio-cultural do estudante.

\section{Palavras-chave}

Ensino Médio Politécnico, Interdisciplinaridade, Concepções Docentes

\section{Marco Teórico}

Pensar em formas e atitudes para mudar a perspectiva de ensino atual tem se tornado um dos grandes desafios para os estudiosos em educação, não em uma visão exacerbada a mudança radical de problemas focados na realidade cultural e social, mas na maneira de inserir nesta realidade relações com o conhecimento científico. Ao tocante, o trabalho em equipe, para maravilhar a realidade e o trabalho coletivo nas escolas públicas, por meio de atividades de

\footnotetext{
${ }^{1}$ Universidade Federal do Rio Grande do Sul. bedin.everton@gmail.com

${ }^{2}$ Universidade Federal do Rio Grande do Sul. delpinojc@yahoo.com.br
} 
Revista Tecné, Episteme y Didaxis: TED. Año 2014, Número Extraordinario. ISSN Impreso: 0121-3814, ISSN web: 2323-0126

Memorias, Sexto Congreso Internacional sobre Formación de Profesores de Ciencias. 08 al 10 de octubre de 2014, Bogotá

inter-relacionamento das diferentes disciplinas, pode derivar em reflexos sobre ações e atitudes articuladas pelos professores.

Nesta esfera, a interdisciplinaridade emerge com o significado de dialogar e articular os conhecimentos disciplinares, enriquecendo cada disciplina que compõe o currículo, não as fragilizando, pois se acredita que esse processo pode fortalecer a forma do educando adquirir conhecimento, já que não se trata de dissolução de conteúdos, mas de uma maneira de emancipar a formação cidadã por meio de um novo currículo.

Assim, nasceu no estado do Rio Grande do Sul, a proposta de reestruturação no Ensino Médio, constituída na perspectiva de assegurar ao educando o acesso à instituição de ensino, aos diferentes saberes, à aprendizagem e a permanência na escola, emergindo o Ensino Médio Politécnico, o qual tem como um dos princípios orientadores a interdisciplinaridade.

Deste modo, cabe ao professor estar fundamentado e apropriado com seu componente curricular (saberes específicos da disciplina) para relacionar o conhecimento científico com os meios de produção ou com outros componentes curriculares que serão suportes para a transformação do conhecimento de senso comum do educando.

Uma das maneiras possíveis para corroborar a este desenho é o entrelaçamento entre as várias áreas do conhecimento (Ciências da Natureza, Linguagens, Humanas e Matemática), antes separadas por disciplinas - analise a figura abaixo - onde a legislação vigente aponta para a adoção de programas de ensino voltados a integração dos saberes de forma interdisciplinar.

Imagem 1. Relação das disciplinas por áreas do conhecimento

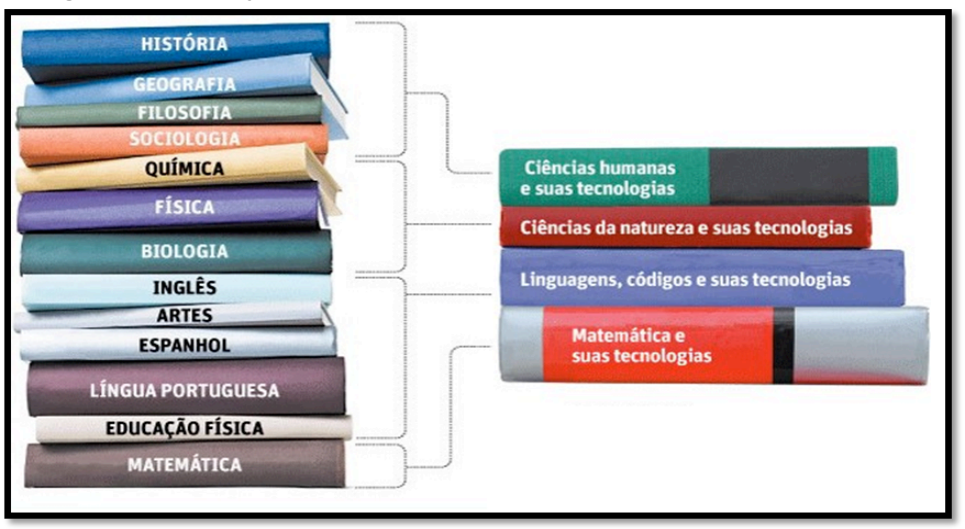


Revista Tecné, Episteme y Didaxis: TED. Año 2014, Número Extraordinario. ISSN Impreso: 0121-3814, ISSN web: 2323-0126

Memorias, Sexto Congreso Internacional sobre Formación de Profesores de Ciencias. 08 al 10 de octubre de 2014, Bogotá

Apesar de a interdisciplinaridade ter chegado ao Brasil no final da década de 60, desempenhando fortes influências na construção da Lei de Diretrizes e Bases (LDB) $5.692 / 71$ e, desde então, sua presença estar confinada no cenário educacional brasileiro, extrapolando-se à LDB 9.394/96 e aos Parâmetros Curriculares Nacionais (PCN), ainda é percebível na maioria das escolas públicas brasileiras um trabalho docente fragmentado e enraizado na dicotomia da dialogicidade e da praticidade.

Nesta perspectiva, "para os PCNs (2002, pág. 88-89), interdisciplinaridade supõe um eixo integrador, que pode ser o objeto de conhecimento, um projeto de investigação, um plano de intervenção". Nesse sentido, ela deve partir da necessidade sentida pelas escolas, professores e estudantes de explicar, compreender, intervir, mudar, prever, algo que desafia uma disciplina isolada e atrai a atenção de mais de um olhar, talvez vários.

Portanto, a construção do conhecimento discente pode derivar-se de muitos vieses, mas, em especial neste artigo, deu-se ênfase a questão da interdisciplinaridade das áreas do conhecimento, a qual oferece uma diferente postura da obtenção deste conhecimento, afinal transforma o educando em um ser autônomo, crítico e reflexivo, pois as práticas docentes fazem deste, ator da própria construção do saber e, portanto, deve buscar subsídios para contextualizar o conhecimento que se confere.

\section{Metodologia e Resultados}

Buscando alcançar o objetivo do presente artigo, entender e refletir, por meio das concepções docentes à luz do Ensino Médio Politécnico, sobre as prioridades que compõem o cerne da interdisciplinaridade, aplicou-se no ano de 2014, um questionário estruturado referente ao tema aos professores cadastrados no senso escolar do ano de 2013 que desenvolveram atividades com os estudantes do segundo ano do EMP.

O questionário foi estruturado em questões dissertativas e objetivas, o qual visou coletar desde concepções pessoais e profissionais até dados referentes ao desenvolvimento docente (saberes específicos), considerando os conhecimentos prévios a respeito da temática estabelecida. 
Revista Tecné, Episteme y Didaxis: TED. Año 2014, Número Extraordinario. ISSN Impreso: 0121-3814, ISSN web: 2323-0126

Memorias, Sexto Congreso Internacional sobre Formación de Profesores de Ciencias. 08 al 10 de octubre de 2014, Bogotá

É de suma importância ressaltar, neste meio, que os resultados abaixo apresentados são extensíveis a realidade dos professores, desde que guardada suas devidas proporções, subentendendo-se que os sujeitos da pesquisa, na qual se deu a aplicação do questionário, é tida como uma população de amostra da totalidade dos funcionários da Escola Estadual de Ensino Médio Antônio Stella.

A pesquisa desenhou-se com a participação de oito professores, dentre eles dois do sexo masculino. Quanto a faixa etária, 38\% possuem idade superior a 41 anos, $37 \%$ com idade entre os 35 e 40 anos o restante, $25 \%$, com idade entre 23 e 28 anos. Acredita-se que se possibilitou aos professores explanarem suas concepções a respeito da interdisciplinaridade no EMP.

A primeira questão realizada aos professores foi: o que você entende por interdisciplinaridade? Em suma, os professores compreendem interdisciplinaridade como uma interação entre as disciplinas trabalhando um mesmo tema, isto é, "para o professor $\mathbf{Q}$ (2014) é uma forma didática de inter-relacionar as diferentes disciplinas em um trabalho comum". Corroborando com essa ideia "H (2014) afirma ser um processo dialógico entre as disciplinas, favorecendo a construção do saber".

Diante dos fatos, percebe-se que os professores compreendem, mesmo que superficialmente, o significado intrínseco da interdisciplinaridade, pois necessitam do auxílio do outro para desenvolver o trabalho docente. Neste desenho, "segundo Japiassu (1975, pág. 30) "a interdisciplinaridade se caracteriza pela intensidade das trocas entre os especialistas e pelo grau de integração real das disciplinas no interior de um mesmo projeto de pesquisa", "assim como Vilela e Mendes (2003, pág 529) "interdisciplinaridade é considerada uma inter-relação e interação das disciplinas a fim de atingir um objetivo comum".

Levando em consideração a necessidade da coletividade das disciplinas para a emersão da interdisciplinaridade, questionaram-se os sujeitos sobre o que é necessário para a interdisciplinaridade se tornar uma realidade efetiva na escola. Para tanto, proporcionaram-se aos professores quatro opções, sendo que as mesmas deveriam ser ordenadas de acordo com a necessidade, sendo o número 1 para a de maior prioridade e o número 4 par a de menor prioridade. (Ver Gráfico 1). 
Revista Tecné, Episteme y Didaxis: TED. Año 2014, Número Extraordinario. ISSN Impreso: 0121-3814, ISSN web: 2323-0126

Memorias, Sexto Congreso Internacional sobre Formación de Profesores de Ciencias. 08 al 10 de octubre de 2014, Bogotá

Gráfico 1. Relação dos professores sobre as categorias prioritárias.

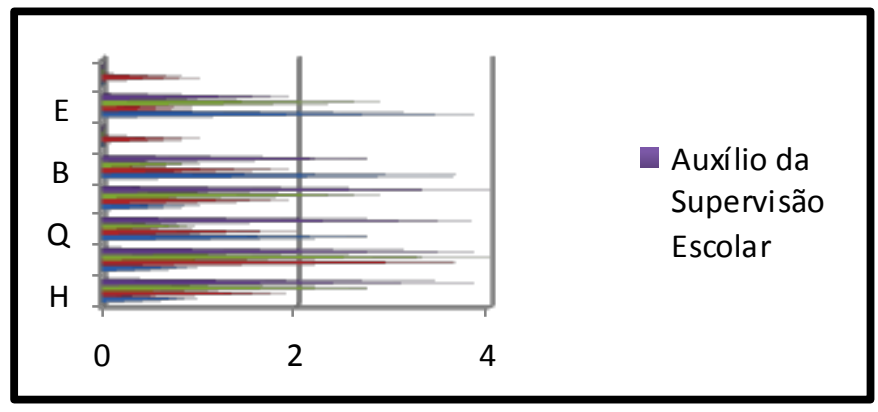

Analisando o gráfico, pode-se perceber que as categorias Políticas Públicas e Currículo Adaptado/Flexibilizado são as duas categorias que os professores dividem como prioritárias para a interdisciplinaridade fazer parte dos trabalhos docentes dentro das atividades desenvolvidas no EMP, perceptível o percentual de $75 \%$ entre as duas. Tendo como segunda opção selecionada pelos professores a categoria Formação Docente, em um percentual de 25\%. Outro dato interessante que deve ser discutido é a categoria Auxílio da Supervisão, pois aparece em 50\% como a última prioridade para este elo, isto é, os professores entendem que trabalhos interdisciplinares devem partir, quase que em sua totalidade, pela vontade e desejo do docente em realizá-los.

A colaboração entre as políticas públicas e a flexibilidade de um currículo escolar de diferentes áreas do saber pode-se derivar em uma possível solução para problemas de ordem prática enfrentados pelos profissionais de diferentes áreas do conhecimento, já que "segundo Frigotto (1997, pág. 26) "a questão da interdisciplinaridade se impõem como necessidade e como problema fundamental no plano histórico-cultural e no plano epistemológico".

Desta forma, a interdisciplinaridade cresce na medida em que se aceita a ideia do outro, necessitando de práticas pedagógicas de mais de um professor, uma vez que pode estar incorporada no plano de trabalho da escola, ramificando-se aos professores por meio de um objeto de projeto, com um planejamento específico, envolvendo dois ou mais professores, com tempos e espaços próprios.

Após compreender o que os professores entendem por interdisciplinaridade, assim como as prioridades que eles aclaram serem importantes para a emersão da mesma, questionou-se os sujeitos como se avalia a questão interdisciplinar na escola. Neste meio, forneceram-se quatro opções aos professores, das quais eles deveriam apontar apenas uma. (Ver Gráfico 2). 
Revista Tecné, Episteme y Didaxis: TED. Año 2014, Número Extraordinario. ISSN Impreso: 0121-3814, ISSN web: 2323-0126

Memorias, Sexto Congreso Internacional sobre Formación de Profesores de Ciencias. 08 al 10 de octubre de 2014, Bogotá

Gráfico 2. Interdisciplinaridade na prática docente

\section{Interdisciplinaridade no contexto escolar}

Necessário, somente em minha área

Necessário, mas com meu apoio

Necessário, desde que independente da minha área

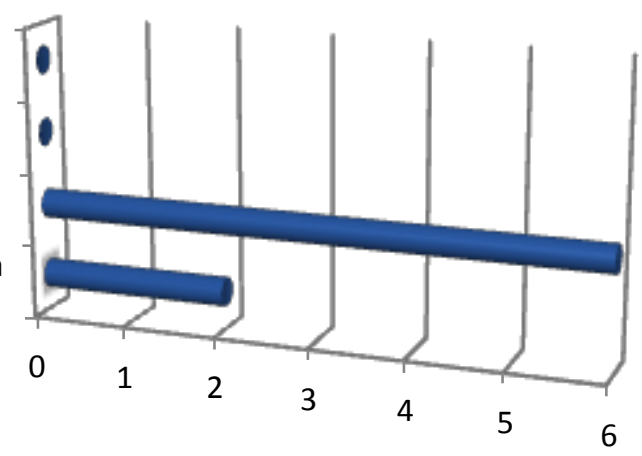

No gráfico, é visível que, dentre as categorias apresentadas no questionário, por forma qualitativa e quantitativa, a categoria: Necessário, mas com meu apoio, obteve $75 \%$ da votação, sendo que a categoria: Necessário, desde que independente da minha área, teve $25 \%$ da votação. As categorias definidas como: Necessário, somente em minha área e Desnecessário, não foram validadas pelos sujeitos da pesquisa. Entende-se, portanto, que é necessário à luz dos resultados, ressaltar quanto às concepções dos professores, enquanto sujeitos do ensino, que a interdisciplinaridade passa a ser vivenciada na escola e, principalmente, no trabalho docente quando os professores trabalham de forma coletiva.

Desta forma, "segundo Ferreira (2005, pág. 34,35) [...] "a interdisciplinaridade por um movimento ininterrupto, passa a criar ou recriar outros pontos para a discussão. [...] Não há interdisciplinaridade se na há intenção consciente, clara e objetiva por parte daqueles que a praticam. [...] A apreensão da atitude interdisciplinar garante, para aqueles que a praticam, um grau elevado de maturidade".

A interdisciplinaridade, neste desenho, não pode ser entendida como uma junção de conteúdos ou métodos, mas uma forma de privilegiar o trabalho 
Revista Tecné, Episteme y Didaxis: TED. Año 2014, Número Extraordinario. ISSN Impreso: 0121-3814, ISSN web: 2323-0126

Memorias, Sexto Congreso Internacional sobre Formación de Profesores de Ciencias. 08 al 10 de octubre de 2014, Bogotá

interativo mediado por conhecimento diversificado, buscando minimizar a linearidade do currículo escolar por meio das competências e habilidades que passam a existir na relação com o outro, apoiando-se na associação de ensino, pesquisa e trabalho. Assim, é perceptível que a concepção sobre interdisciplinaridade de que se tratou no presente artigo, para além de compreende trocas e cooperações entre as diferentes disciplinas, buscou uma verdadeira integração entre os professores e os estudantes, de modo que as fronteiras entre eles se tornassem invisíveis e que, neste anseio, ambos pudessem construir saberes e conhecimentos de forma construtiva, ética e conjunta.

\section{Conclusão}

Romper com os paradigmas docentes sobre a forma tradicional de trabalhar é difícil, pois a escola sempre teve uma grande e aparente dificuldade em lidar com a pluralidade e as diferenças e/ou semelhanças que aparecem entre as diversas disciplinas. Neste desenho, os professores preferem o silêncio e a neutralização das múltiplas informações, pois abrir espaços para o diálogo, as diferenças entre a forma didática de trabalho e o cruzamento de ideias entre os diferentes professores é modificar toda a estrutura educacional, rompendo com o silêncio e a fragilidade dos estudantes.

De fato, hoje se percebe que alguns professores não se situam mais no espaço do comodismo e da mesmice, rasgando a teia da neutralidade e chegando a realidade em que o educando se encontra, reformulando sua formação e atualizando suas práticas pedagógicas alicerçadas a ideia da interdisciplinaridade, para que haja um enfrentamento na crise atual que a escola e a educação enfrentam com as dificuldades da reestruturação do currículo.

As relações que os professores desempenham com as concepções sobre interdisciplinaridade vão além dos saberes profissionais, didáticos ou profissionais, pois se colocam em uma situação diferenciada com aquela que ocorre, predominantemente, nas escolas públicas de ensino. Sendo assim, pode-se afirmar que quando se trabalha as questões do científico no viés da interdisciplinaridade ao cerne da realidade da politecnia no senso comum do educando, corrobora-se para a constituição da identidade do mesmo, da construção do saber e no convívio com o outro, agrupando ideias onde os professores consigam perceber que não existe um modelo padrão de ensinar, 
Revista Tecné, Episteme y Didaxis: TED. Año 2014, Número Extraordinario. ISSN Impreso: 0121-3814, ISSN web: 2323-0126

Memorias, Sexto Congreso Internacional sobre Formación de Profesores de Ciencias. 08 al 10 de octubre de 2014, Bogotá

mas que todo e qualquer desenvolvimento de atividade docente se torna mais rico e prazeroso para o estudante quando desenvolvido na coletividade das diferentes disciplinas.

Não obstante, deve-se considerar que um trabalho disciplinar busca unidade de trabalho docente para/e construção de saber discente, mesmo antes de garantir associação temática entre diferentes disciplinas, pois se acredita que um trabalho deste porte favorecerá a aprendizagem do estudante e sua construção sóciocultural seja por meio de diferentes fontes expressas em diferentes linguagens ou por diferentes interpretações sobre os temas trabalhados em sala de aula.

Destarte, é cabível mencionar os trabalhos que a os professores, na relação da escola com a comunidade escolar, estão desenvolvendo com os estudantes no que tange a Sustentabilidade Ambiental, pois desta forma se estabelece pontes de relações entre as disciplinas, as didáticas, complementações e construção de saber, afinal a interdisciplinaridade emerge não apenas para fazer a relação nas áreas, mas para que o estudante possa aprender nesta relação.

\section{Referências bibliográficas}

Ferreira, S.L. (2005). Introduzindo a noção de interdisciplinaridade. In I.C.A.Fazenda, Práticas interdisciplinares na escola (pág. 33-35). São Paulo: Cortez.

Frigotto, G. (1997). A interdisciplinaridade como necessidade e como problema nas ciências sociais. In A.P.Jantsch. \& L.Bianchetti, Interdisciplinaridade: para além da filosofia do sujeito. Petrópolis: Vozes.

Japiassu, H. (1975). Interdisciplinaridade e patologia do saber. Rio de Janeiro: Âmago.

Lei de Diretrizes e Bases da Educação Nacional - LDB n 5.692 de 05 de novembro. Congresso Nacional - Brasil - Brasília.

Lei de Diretrizes e Bases da Educação Nacional - LDB n 9.394/96 de 20 de dezembro. Congresso Nacional - Brasil - Brasília.

Parâmetros Curriculares Nacionais + (PCN+). (2002) Ciências da Natureza e suas Tecnologias. Ministério da Educação. Secretaria da Educação Média e Tecnológica - Brasil - Brasília,. 
Revista Tecné, Episteme y Didaxis: TED. Año 2014, Número Extraordinario. ISSN Impreso: 0121-3814, ISSN web: 2323-0126

Memorias, Sexto Congreso Internacional sobre Formación de Profesores de Ciencias. 08 al 10 de octubre de 2014, Bogotá

Vilela, E. \& Mendes I.J.M. (2003). Interdisciplinaridade e saúde: estudo bibliográfico. Latino-am Enfermagem, 11 (4), pág. 525-531. 